\title{
Challenges and perspectives for the protection of masonry structures in historic centers: the role of innovative materials and techniques
}

\author{
Maria Rosa Valluzzi ${ }^{a^{*}}$ \\ a Department of Cultural Heritage, University of Padova, Piazza Capitaniato 7, 35131 Padua, Italy \\ Received: 31 May 2016 / Accepted: 10 June 2016 / Published online: 22 June 2016 \\ (C) The Author(s) 2016. This article is published with open access.
}

\begin{abstract}
Lessons learned from natural events which caused severe damage to existing constructions have repeatedly shown the high vulnerability of historically important masonry, often worsened by inaccurate or dubious applications of modern or innovative interventions. Especially in the field of new technologies and materials applied to historical assets, experimental validation integrated at multi-disciplinary level is essential, to implement correct choices able to balance the respect of tradition and the requirements of innovation. The common objective is the transmission of educational values through the conservation of the historical identity of constructions which have survived over time and are still functional today. Planning agreements among academic and industrial research, management and governing bodies constitute preconditions for selecting consistent strategies for the protection of the built environment. However, the effects of technical advances and trends on historical assets should be carefully evaluated when influencing common practices, before recommendations, standards or execution protocols based on sufficiently long-lasting experience are available. This paper discusses a series of issues involved in the complex process of methodological and operative options currently feasible in the field of historical masonry structures. It also focuses on the progressive role of composite materials and the consequent implications on the implementation of preservation criteria.
\end{abstract}

Keywords: Masonry; Preservation; Composites; Compatibility; Sustainability

\section{Introduction}

Masonry composes a large stock of historical structures still standings over centuries, despite natural and also often anthropic hazards. Not only earthquakes, floods and landslides, but also constructions and infrastructures, in some conditions, may represent severe environmental risks for the population. In this case, protection involves management on a territorial scale, to limit exposure to hazard by means of suitable local strategic plans and predictive analyses [1, 2]. However, the destructive potential of natural hazards is frequently rendered worse by human actions (when not provoked, sometimes deliberately, by war, terrorism, etc., or induced by subterranean extractions, e.g. mining, fracking or gas drilling). Damage scenarios observed in past (and also unfortunately still more recent) events, e.g., earthquakes, have shown that extensive and severe losses occur even at moderate local magnitude (around 5-6 MI) [3-5], highlighting the great vulnerability of buildings. The causes may be found on several aspects. On one hand, it is well-known that ancient masonry structures may include defects in construction details, and even in structural conception, or in execution, and that deterioration phenomena due to environmental exposure can weaken the properties of materials (reduced bonding capacity of mortars due to binder dissolution in water, chipping and losses due to erosion, etc.). In this case, proper understanding of the historical concepts of structural mechanics [6], critical survey of actual conditions, proper improvement measures (if needed), monitoring and assiduous maintenance programs may form part of a beneficial conservation strategy.

On the other hand, it is clear that structures still standing today have not only, in many cases, resisted for centuries, because they were structurally well conceived and built with good-quality materials and care in execution details; they still survive essentially because they have been used (in the sense that they have not been neglected or abandoned), not necessarily as buildings with a specific ongoing function, but also as historical evidence of our recognizable past - ruins, archeological sites, or isolated monuments [7]. Nevertheless, making use of ancient constructions today also means identifying in their history a number of modifications and changes aimed at functional or structural upgrading, which may have deeply transformed or even, occasionally, completely reconstructed those existing buildings.

As a matter of fact, interventions play a significant role in the process of renewing and upgrading existing buildings. In this context, the point which seems particularly contradictory, 
and still problematic, although confirmed by several observations, is that works designed to improve structural behavior actually caused extensive, severe damage. Collapse induced by the intrusion of reinforced concrete (RC) elements into existing masonry buildings to replace floors and roofs, support vaults and domes, or connecting walls as tie-beams are, unfortunately, very well-known (Fig. 1) [3, 5, $8,9]$. Their dangerous effects are often detected in buildings made by multi-leaf masonry walls, revealing poor quality and lack of connections among layers and components; this condition essentially identify the worst combination with heavy diaphragms.

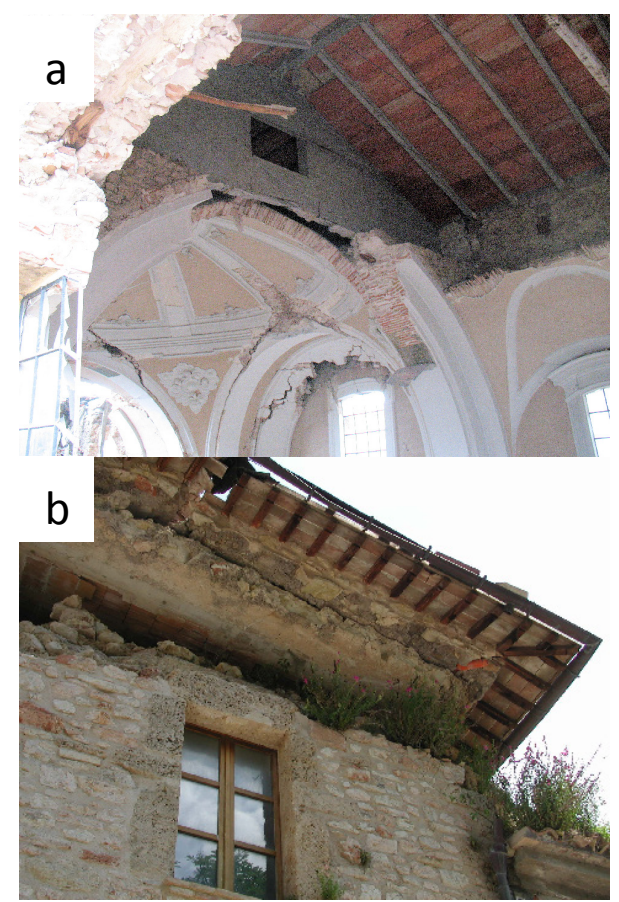

Figure 1. Effect of replacement of traditional roofs with RC components after earthquake damage: (a) collapse of vaults; (b) crushing and overturning of walls.

Actually, increased and uneven distribution of masses, together with lack of complementary and integrated functioning of structural components, lead to mixed behavior, very far from the desired box-like result. This is theoretically effective when the buildings in questions are subjected to seismic action, but it is practically achievable with such measures only in new buildings or, in some cases, when entire storey remaking (e.g., roof) is needed. The loss of continuity in wall sections (particularly for the piers), weakened by grooves in the masonry to hold RC components, should be seriously evaluated, in the same way as the possible presence of cavity or recesses (e.g., due to exhaust pipes), lack of alignment, or uneven distribution of openings on façades. Techniques which reduce the resisting section of masonry components should in fact be considered as causes of pre-damage, as they also reduce the capacity for redistribution (particularly for compression loads) of massive components such as pillars or walls.

The reason why the choice to apply such intervention techniques has been possible for decades is the altered, inconsistent concept between the theoretical and actual behavior of existing buildings, particularly in the complex contest of masonry structures.

The inescapable basis of intervention projects must thus always be the knowledge process, supported by suitably identified experimental procedures and modeling tools, capable of representing the real behavior of the building, together with awareness of the unavoidable level of approximation [10]. Such a knowledge process should be able to indicate a cautious and responsible approach to existing constructions [11], so that gaps in our understanding and prediction of effects can emerge, as well as possible solutions.

\section{Scientific and technical support to knowledge}

In the field of uncertainties discussed above, it is clear that experimental investigations and detailed studies (both laboratory simulations and direct testing in situ) play an essential role in integrating knowledge. The scientific community (academic, research centers), often working efficiently with manufactures and companies, authorities and institutions, have increasingly contributed to developing procedures and techniques aimed at improving the mechanical performance of existing structures and their durability [12]. On one hand, these mutually beneficial connections, have led to continual upgrading of the implementation of the concepts of preservation or restoration on a real scale, so that technical advances in materials and techniques, procedures and methods (theoretical models, numerical approaches) constantly pervade strategies and approaches. On the other hand, some aspects should be taken also into consideration, especially in the ongoing interest in and focus on innovation in the field of retrofitting and strengthening of existing structures. They are basically linked with the mismatch between the time and the resources needed for research validation (which may be particularly long in the case of experimental testing, but clearly essential within the new perspectives of application and use) and market and development demands. This often leads to a rush of applications on constructions (even in the historical context), practically without any rules for design an assessment, or even reliable indications regarding execution, or awareness of short- and long-term effects on the effectiveness of the techniques applied. Both errors in design and defects in construction details may be direct consequences of such a lack of knowledge and uncertainty about future behavior. This phase, intended to be temporary, may last several years or even decades, which is long enough to cause an increase in improper practices, and probably also situations of vulnerabilities. This is quite contradictory, as interventions should aim at reduce vulnerability, instead of increase it. In addition, as has already occurred in various fields of calamities (not only earthquakes), a new event suddenly highlights these deficiencies when they were not sufficiently evaluated earlier, leading to high casualty rates and the loss of built assets $[3,5]$. Obviously, such a mismatch between scientific validation and practice has repercussions on the 
drafting and issuing of standards, related to both experimental procedures and design and appraisal. As a consequence, such problem covers all aspects, from general concepts to specific details concerning design, assessment and effectiveness control.

Similarly, innovative materials applied within the last three decades to existing masonry, composites like Fiber Reinforced Polymers (FRP), have rapidly spread, due to their high potential in increasing mechanical performance of materials lacking ductility and tensile strength. In particular, FRPs have been mainly applied to masonry components as Externally Bonded Reinforcement (EBR) systems, e.g., with carbon or glass textiles and, to a smaller extent, with preimpregnated laminates [13]. This has happened even though some recommendations and guidelines were only available at beginning of this century [14, 15], which essentially neglect the undesirable effects of epoxy resins over time. This situation has led to generalized interventions, often revealing lack of experience or proper knowledge of mechanical functioning. This can be seen, for instance, in over-abundance of the amount of fibers (several overlapping layers, excessive width), which causes problems in terms of water permeability on the substrate surface, or inaccuracy in details (particularly at anchoring level), which influences the effectiveness of the intervention itself.

Only shortly after FRP recommendations were issued, further reinforcing systems developed in the field of repair and strengthening of masonry, this time with better matching compatibility, removability and sustainability, i.e., Fiber Reinforced Cementitious Matrix (FRCM), Textile Reinforced Mortar (TRM), or Inorganic Matrix Grid (IMG), composites which assemble fiber meshes within an inorganic matrix. Steel fibers and bio-composites (natural fabrics based, e.g., on hemp, flax, or jute) are included in this trend. Increased knowledge of FRPs, thanks to considerable scientific works, has encouraged several studies on inorganic matrix-based interventions [16-18], as well as further applications to existing structures [19]. Drafting of guidelines for FRCM composites, homogenization of procedures, terms of installation and effectiveness control, as well as prediction of behavior of components and structures, are currently in progress (ACl 549.4R [20] is available in the US, but virtually no guideline is available on composites qualification), so that, yet again, proper support for applications to existing structures are still lacking.

Nevertheless, it must be recognized that outstanding efforts have been made by research and academic associations, manufactures, and stakeholders in working groups, often coordinated at international level within the framework of integrated projects, to share knowledge and improve awareness of the effects of interventions on existing masonry structures. Significant results of such synergies are the drafting of pre-normative documents (RILEM, ACI) and dissemination tools, e.g., advanced open access databases, which can collect data in more user-friendly formats and be directly updatable in real time with further research results (RILEM TC 223-MSC data warehouse [21], NIKER catalogue [22]). Such tools need to be sufficiently widespread at educational, professional and management levels, as they represent useful supports to maintain essential updating of potential and direct operators, based on scientific validation and experience.

\section{Tradition and innovation for interventions on existing masonry}

The binomial tradition-innovation has traversed the history of built assets for centuries. The debate, still open, particularly in the sphere of protection from seismic hazard, repeatedly makes us aware of the knowledge gap between the static concept of ancient constructions and modern advances in terms of materials, techniques and calculation tools. Conversely, current modeling of ancient configurations which have been extensively transformed over time through upgrading to new static and functional conditions or the availability and supply of new constructive materials, may be only very approximate, indicating possible unreliability, or at least caution in interpreting results.

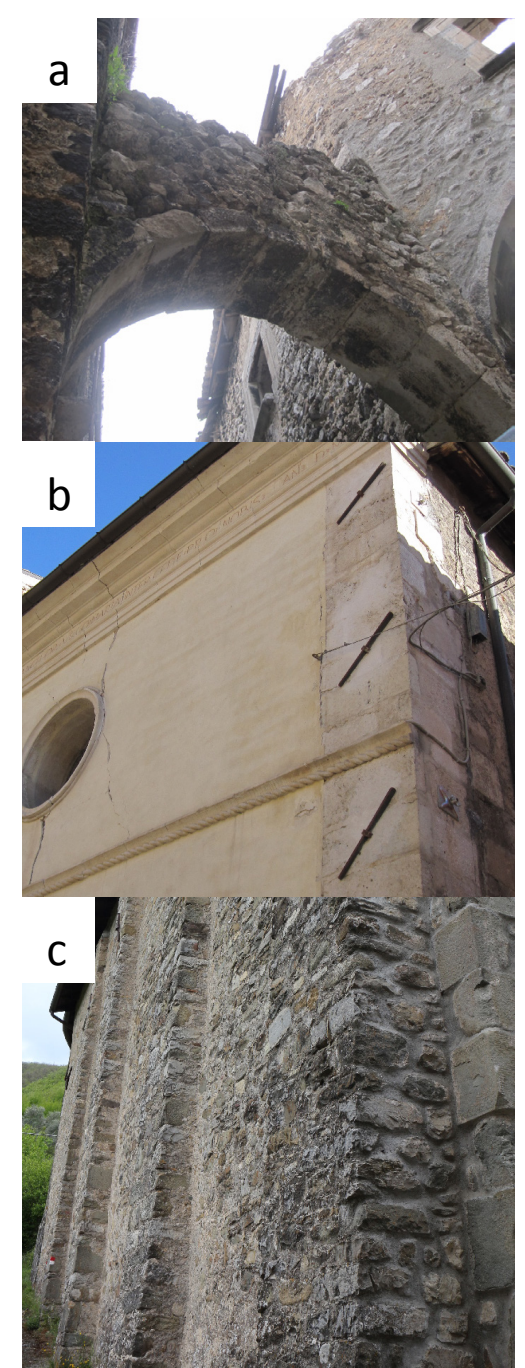

Figure 2. Historical preventive measures for defense against earthquakes: (a) external arches; (b) metal ties; (c) buttresses. They counteract overturning of façades, thrust of vaults and arches, and provide better distribution of compressive stresses on masonry wall sections. 
Ancient constructions often reveal signs of historically old interventions, validated by direct experience. Restraint by small arches or by ties, or support by buttresses (Fig. 2) are simple but direct and therefore effective solutions to counteract spatially unbalanced consequences such as outof-plane collapse [23].

At component scale, it is therefore often sufficient to reestablish resistant masonry sections, if weakened by damage or failure, without adding excessive further strength [24], unless reinforcement of specific performance (e.g., tensile strength) is required, taking care of improving concurrently the redistribution of stresses and the occurring of brittle mechanisms.

Clearly, interventions to existing structures to repair damage, or strengthening and retrofitting to prevent it, should focus on the specific structural deficiency, and proper materials must be select to avoid worsening of current conditions from the physical, chemical and mechanical viewpoints. As a matter of fact, in the field of ancient constructions, one of the most basic criterion is certainly compatibility. Although this concept is quite wide, covering both materials and techniques, it also includes also other aspects, e.g., minimum alteration of functions (understood as use of the asset, but also as the role played by structural components) and respect of aesthetics. Compatibility is thus broadly related to other criteria, such as durability, minimal obtrusiveness and, when possible, removability.

Certainly, the wide appeal of EBR with FRP composites initially reflected the essential contribution of tensile

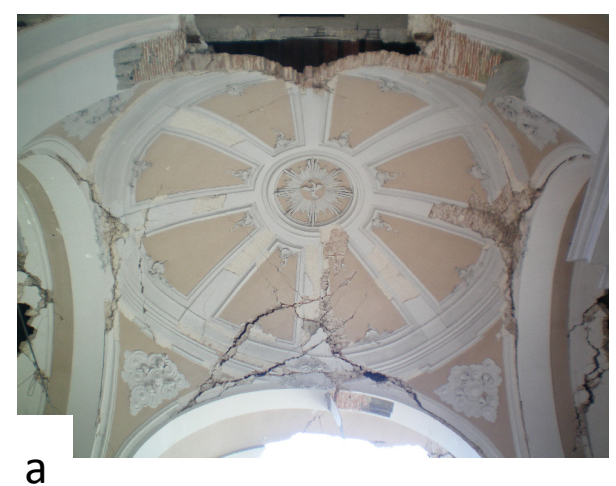

basalt net strip acting as confinement of circular

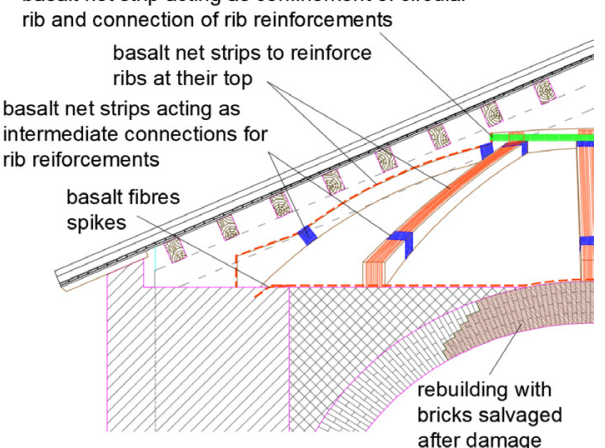

capacity to masonry, and the consequent modification of brittle collapses in favor of pseudo-ductile mechanisms.

This improvement is obtained without adding excessive mass by means of corrosion-free resistant materials, which are also easy and quick to install and able to activate their performance with short curing times. All of these are outstanding advantages in comparison with previous interventions involving RC elements. Later, compatibility requirements, with all the implications described above, and an increasing attention to sustainability, directed the research community toward composites applied with inorganic matrixes. These materials have low overall performance compared with FRPs, although they are sufficient to improve the overall behavior of masonry components and whole buildings: reduced cracking and diffusion of damage instead of concentration, and considerable strength and displacement capacity are the main benefits $[25,26]$. Particularly effective are composites for strengthening and retrofitting vaults, otherwise extremely prone to brittle collapse during seismic events [27, 28]. Composite nets applied with hydraulic lime-based mortars at the extrados of vaults, combined with all other interventions needed to improve the whole structure, e.g., reintegration of units and bed joints, repair of cracks, confinement of lateral thrust, and partial rebuilding, all turn out to be valid solutions against brittle behavior. An example of possible retrofitting of vaults with currently common composite materials is shown in Fig. 3.
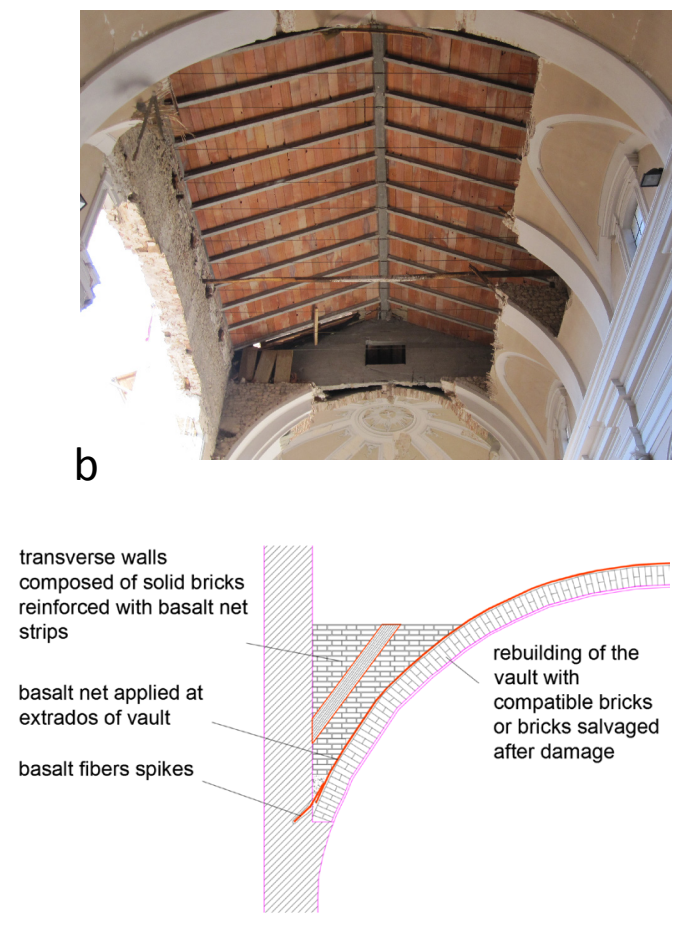

Figure 3. Damage conditions (photos) and intervention proposals (schematic drawings) for church of S. Marco in L'Aquila, struck by 2009 earthquake: (a) dome and (b) main nave barrel vault. Details of intervention with TRM with basalt net and hydraulic lime-based matrix (courtesy of SM Ingegneria s.r.I., Padova). 


\section{Conclusions}

Historical structures represent a considerable sign of our cultural identity. Respect for and understanding of our history involve appropriate and responsible activities applied at different scales to buildings and city centers. Preservation of historical masonry in hazardous conditions is particularly challenging, as it entails several complex aspects - not only diverse sectors and types of expertise, but also a number of uncertainties and approximations. These concern the identification and prediction of actions, knowledge of ancient materials, and interpretation of structural behavior. Last but not least, they concern the evaluation of interactions with modern or innovative solutions, designed and understood as improvements. Risk mitigation also involves recognition of changes over time and proper prediction of the effects of identified vulnerable aspects. Monitoring is an effective tool to complete conservation strategies and minimize interventions.

Composites have rapidly reached a leading position in the context of retrofitting of existing structures, including ones of historic interest, and recently developed materials and techniques focusing more on compatibility and sustainability. Nevertheless, we should realize that experience of the influence of modern solutions over time has often been contradictory in terms of actual effects on constructions: a general cautious approach is therefore required, combined with a focus on removability. Currently, one of the most problematic questions is how to intervene on operations carried out in the past, buy identified today as possible causes of worsening of the performance of previously strengthened constructions.

Scientific experimentation (both in situ and in the laboratory) is essential to validate innovative materials and techniques, but it must be followed by proper dissemination at academic and professional levels, to provide training and continual upgrading, so that operations in the historical context may emerge as the natural outcome of our cultural enhancement.

\section{Acknowledgements}

The author wishes to thank Prof. C. Modena and Dr. C. Bettio, of SM Ingegneria S.r.l., Padova, Italy, for providing documentation of intervention design.

\section{References}

[1] M. Dolce, A. Masi, M. Marino, M. Vona, Earthquake damage scenarios of the building stock of Potenza (Southern Italy) including site effects. Bull Earthq Eng (2003) 1 (1): 115-140.

[2] D. Worthng, S. Bond, Managing Built Heritage: The Role of Cultural Significance. Wiley, 2008.

[3] L. Binda, G. Cardani, A. Saisi, M.R. Valluzzi, Vulnerability analysis of the historical buildings in seismic area by a multilevel approach. Asian J Civ Eng (Building and Housing) (2006) 7 (4): 343-357.

[4] F. Parisi, N. Augenti, Earthquake damages to cultural heritage constructions and simplified assessment of artworks. Eng Fail Anal (2013) 34: 735-760.
[5] A. Penna, P. Morandi, M. Rota, C.F. Manzini, F. da Porto, G. Magenes, Performance of masonry buildings during the Emilia 2012 earthquake. Bull Earthq Eng (2014) 12 (5): 2255-2273.

[6] A. Giuffrè, Safety and conservation of historical centers: the Ortigia case. Laterza Press, Rome, 1993.

[7] Charter of Venice, International charter for the conservation and restoration of monuments and sites. Decision and resolutions. ICOMOS, Paris, 1964.

[8] M. Tomaževič, The influence of rigidity of floors on the seismic behaviour of old stonemasonry buildings. Eur Earthq Eng (1991) 5 (3): 28-41.

[9] M. Corradi, A. Borri, A. Vignoli, Strengthening techniques tested on masonry structures struck by the Umbria-Marche earthquake of 1997-1998. Constr Build Mater (2002) 16 (4): 229-239.

[10] M. R. Valluzzi, On the vulnerability of historical masonry structures: analysis and mitigation. Mater Struct (2007) 40 (7): 723-743.

[11] C. Modena, Criteria for cautious repair of historic building. A valuation and strengthening of existing masonry structures. L. Binda and C. Modena (Eds), RILEM, 1997.

[12] C. Modena, F. da Porto, M.R. Valluzzi, M. Munari, Criteria and technologies for the structural repair and strengthening of architectural heritage. Int J 3R (Rep Rest Renew Built Env) (2013) 4 (3): 606-621.

[13] A. Balsamo, M. di Ludovico, G.P. Lignola et al, Composites for structural strengthening. Wiley Encyclopedia of Composites, 2011.

[14] CNR-DT 200, Guide for the Design and Construction of Externally Bonded FRP Systems for Strengthening Existing Structures. National Research Council, Italy, 2004.

[15] ACl 440M Guide Draft-1, Guide for the design and construction of externally bonded FRP system for strengthening unreinforced masonry structures. ACl 440 committee, 2004.

[16] A. Prota, G. Marcari, G. Fabbrocino, G. Manfredi, C. Aldea, Experimental in-plane behavior of tuff masonry strengthened with cementitious matrix-grid composites. J Compos Constr (2006) 10 (3): 223-233.

[17] A. Balsamo, M. di Ludovico, A. Prota, G. Manfredi, Masonry walls strengthened with innovative composites. ACl Special Publication (2011) 2 (275): 769-786.

[18] G. de Felice, S. de Santis, L. Garmendia, B. Ghiassi, P. Larrinaga, P-B. Lourenço, D.V. Oliveira, F. Paolacci, C.G. Papanicolaou, Mortarbased systems for externally bonded strengthening of masonry. Mater Struct (2014) 47 (12): 2021-2037.

[19] M.R. Valluzzi, C. Modena, G.M. de Felice, Current practice and open issues in strengthening historical buildings with composites. Mater Struct (2014) 47 (12): 1971-1985

[20] ACl 549.4R, Guide to design and construction of externally bonded fabric-reinforced cementitious matrix (FRCM) systems for repair and strengthening concrete and masonry structures. ACI 549 committee, 2013

[21] RILEM TC 223-MSC Data warehouse. https://rilem223dwh.isqweb.it/ (last accessed May 2016).

[22] NIKER catalogue. New integrated knowledge based approaches to the protection of cultural heritage from earthquake-induced risk. https://niker.dicea.unipd.it/ (last accessed May2016).

[23] M. Tomaževič, M. Lutman, P. Weiss, Seismic upgrading of old brickmasonry urban houses: tying of walls with steel ties. Earthq Spectra (1996) 12 (3): 599-622.

[24] M.R. Valluzzi, F. da Porto, C. Modena, Behavior and modeling of strengthened three-leaf stone masonry walls. Mater Struct (2004) 37: 184-192.

[25] T.C. Triantafillou, C.G. Papanicolaou, Shear strengthening of reinforced concrete members with textile reinforced mortar (TRM) jackets. Mater Struct (2006) 39 (1): 85-93.

[26] C.G. Papanicolaou, T.C. Triantafillou, K. Karlos, M. Papathanasiou, Textile-reinforced mortar (TRM) versus FRP as strengthening material of URM walls: in-plane cyclic loading. Mater Struct (2007) 40: 1081-1097.

[27] L. Garmendia, J.T. San-Jose, D. Garcia, P. Larrinaga, Rehabilitation of masonry arches with compatible advanced composite material. Constr Build Mater (2011) 25: 4374-4385

[28] V. Giamundo, G.P. Lignola, G. Maddaloni, F. da Porto, A. Prota, G. Manfredi, Shaking table tests on a full-scale unreinforced and IMGretrofitted clay brick masonry barrel vault. Bull Earthq Eng (2016) 14 (6): 1663-1693. 